\title{
WestVirginiaUniversity
}

THE RESEARCH REPOSITORY @ WVU

Graduate Theses, Dissertations, and Problem Reports

1999

\section{Obturation with gutta percha of greater taper}

\author{
A. L. Christopher Kayafas \\ West Virginia University
}

Follow this and additional works at: https://researchrepository.wvu.edu/etd

\section{Recommended Citation}

Kayafas, A. L. Christopher, "Obturation with gutta percha of greater taper" (1999). Graduate Theses, Dissertations, and Problem Reports. 968.

https://researchrepository.wvu.edu/etd/968

This Thesis is protected by copyright and/or related rights. It has been brought to you by the The Research Repository @ WVU with permission from the rights-holder(s). You are free to use this Thesis in any way that is permitted by the copyright and related rights legislation that applies to your use. For other uses you must obtain permission from the rights-holder(s) directly, unless additional rights are indicated by a Creative Commons license in the record and/ or on the work itself. This Thesis has been accepted for inclusion in WVU Graduate Theses, Dissertations, and Problem Reports collection by an authorized administrator of The Research Repository @ WVU. For more information, please contact researchrepository@mail.wvu.edu. 
Obturation With Gutta Percha Of Greater Taper

\author{
A. L. Christopher Kayafas, D.D.S. \\ Thesis Submitted to the School of Dentistry of \\ West Virginia University \\ In Partial Fulfillment of the Requirements for \\ The Degree of Master of Science
}
C. Russell Jackson, D.D.S., M.S., Chair
Michael Bagby, D.D.S., PhD
Thomas Razmus, D.D.S., M.S.

\title{
Division of Endodontics
}

Morgantown
West Virginia

1999

Keywords: Dentistry, Endodontics, Rotary instrumentation, Profile, Diadent 
To Lisa, for her love, support and understanding. Thank you for being there for me and being a terrific partner. To my sons, Aristotle Lucas and Noah Christopher, the dream of your future is my inspiration. 


\section{ACKNOWLEDGMENTS}

I would like to thank Dr. C. Russell Jackson for giving me the opportunity to pursue my goal of becoming an endodontist. Russ, thank you for your daily guidance, unique perspective and friendship. You have provided me with a solid foundation upon which to build a career in our specialty.

I would like to thank Dr. Scott Seitzinger for sparking my interest in endodontics and Dr. Troy McGrew for his friendship and the encouragement that he provided to turn that spark into a flame. Dr. Michael Nimmich was a terrific role model to follow and was a fountain of well-grounded advice.

In addition, I would like to thank Dr. Eric Menke for being such a great co-resident to complete the program with. Eric, you are a great friend and I am truly grateful to have had the opportunity to spend the last two years with you.

I would like to thank Dr. Robert Raynes for his valuable input to the program and Dr. Cathy Connor for her encouragement and help over the last year. In addition, I would like to thank Dr. Mike Bagby for his advice, support and willingness to help keep this thesis process moving forward. Also, thanks to Dr. Tom Razmus for his help and guidance over the last few years. Thank you also to Dr. Jerry Hobbs for his willingness to help with the statistical analysis.

I would like to thank Cathy Myers for her daily dedication, friendship and desire to contribute to this program. Thanks also to Marcie Weimer and Gina White for their hard work and unique qualities which help to make this program something special.

Thank you also to Steve Moore for his friendship, reliability and the many hours he has spent assisting me in private practice.

I would like to especially thank my parents, Leonard and Lois Kayafas for providing me with the tools to make my dreams come true. You were the best role models a person could ask for and I hope to be as inspirational for my children as you have been for me. 


\section{TABLE OF CONTENTS}

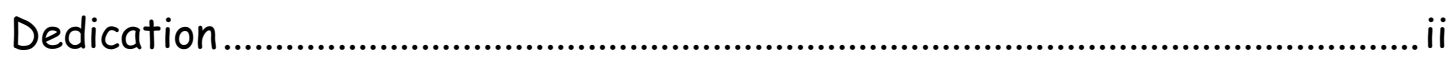

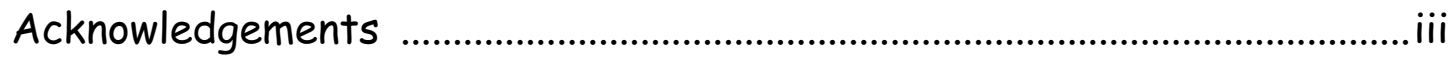

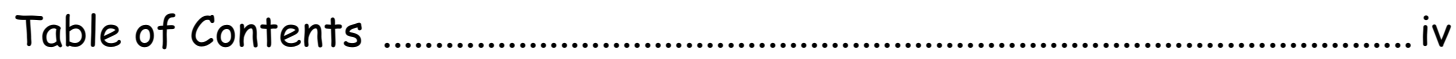

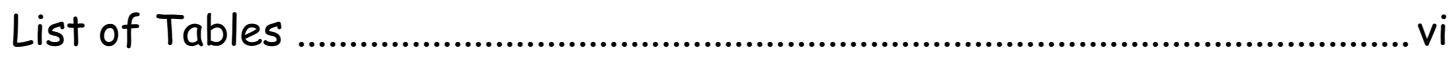

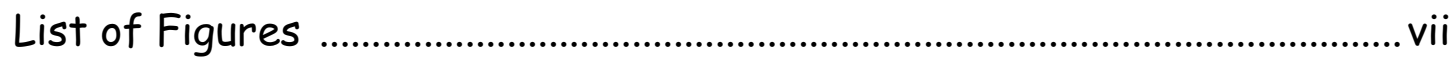

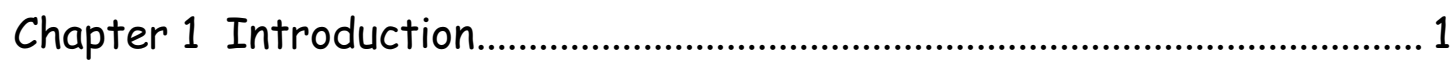

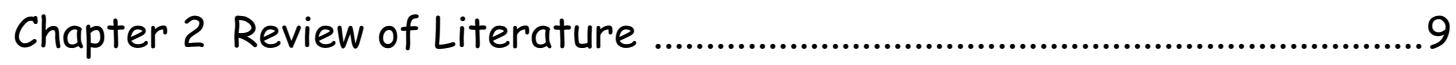

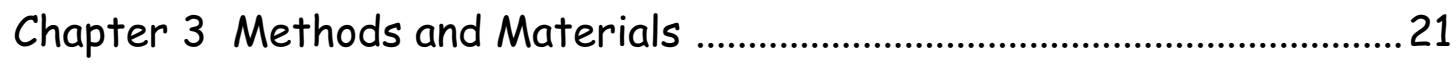

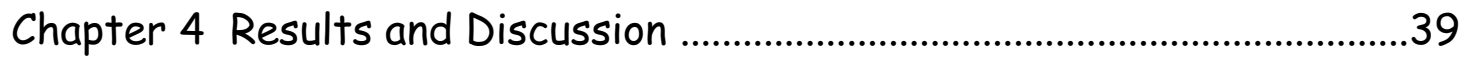

Chapter 5 Summary and Conclusions ........................................................ 53

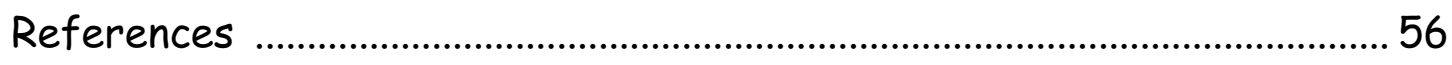

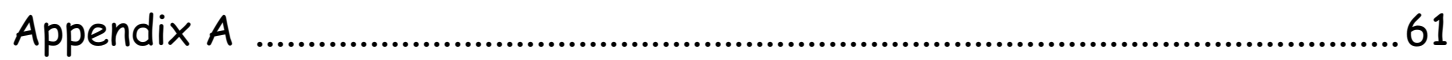

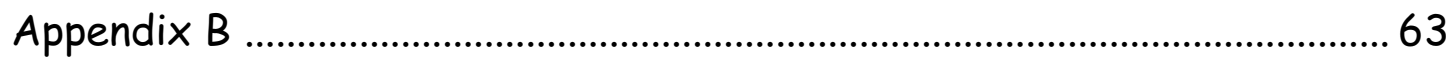

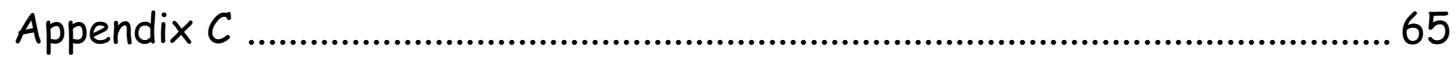

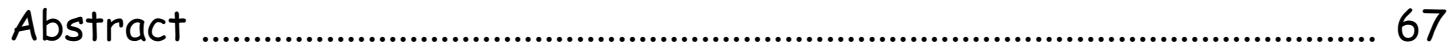




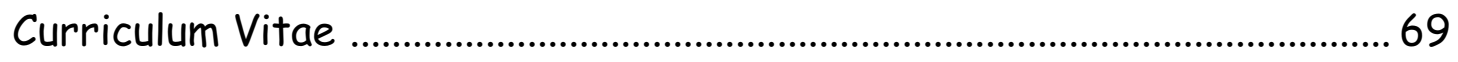

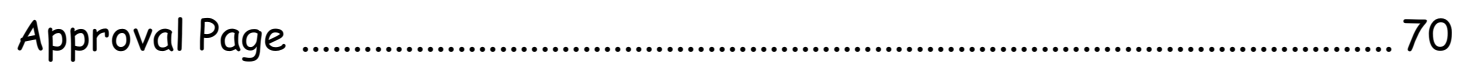




\section{LIST OF TABLES}

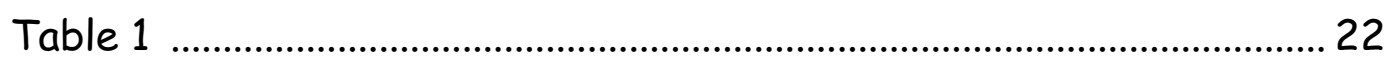

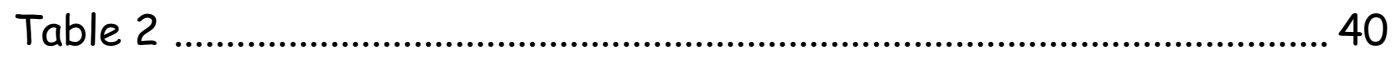

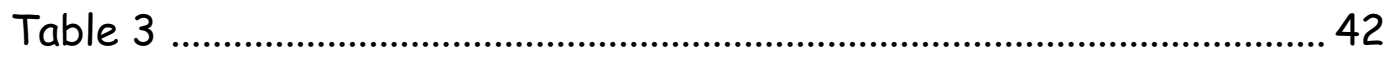




\section{LIST OF FIGURES}

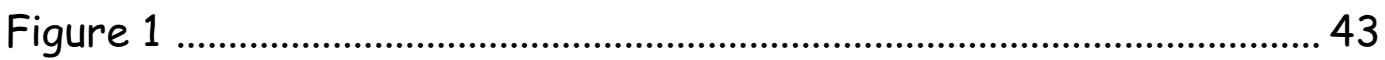

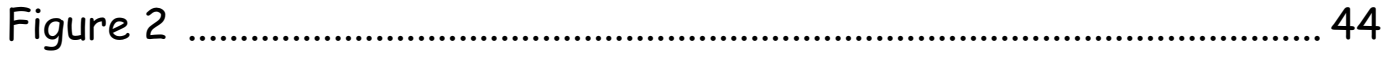




\section{CHAPTER 1}

\section{INTRODUCTION}

Thorough debridement and cleansing of the root canal system is vital to success in root canal therapy (1). The objective of cleaning and shaping is to remove all canal contents and shape the canal in a way that facilitates obturation. Instrumentation directly effects the ability of the operator to properly obturate the canal system (2). To improve the quality of the canal preparation, nickel-titanium files have been developed. The ProFile Series 29 (PRO-29) nickel-titanium files are currently a very popular system of files and they are available in 0.04 and 0.06 taper.

Recently, Diadent has developed gutta percha points which match the size and taper of the PRO-29 files. Diadent claims their DiaPro 0.04 and 0.06 taper gutta percha cones will simplify obturation by providing an exact fit between the master file and the master gutta percha cone.

Many methods have been applied to examine the ability of root canal obturation materials and techniques to prevent leakage. The most popular 
model has been the linear measurement of the penetration of a dye along the interface of the canal wall and the obturating material.

The purpose of this study was to compare the apical dye leakage in the root canals of extracted teeth in four experimental groups: 1) PRO-29, 0.06 taper instrumentation to $2.0 \mathrm{~mm}$ short of working length followed by ISO size hand file instrumentation to prepare the apical $2.0 \mathrm{~mm}$ and obturation with an ISO sized master gutta percha cone using cold lateral condensation; 2) PRO-29, 0.06 taper instrumentation to working length followed by cold lateral condensation with a DiaPro 0.04 taper master gutta percha cone; 3) PRO-29, 0.06 taper instrumentation to working length followed by warm vertical condensation using a DiaPro 0.06 taper master gutta percha cone; 4) PRO-29, 0.06 taper instrumentation to working length followed by obturation with a single DiaPro 0.06 taper master gutta percha cone. 


\section{STATEMENT OF THE PROBLEM}

There have been no studies to evaluate the quality of the apical seal of canals instrumented with the ProFile Series 29, 0.06 taper rotary files and obturated with the Diadent DiaPro 0.04 and 0.06 taper gutta percha points.

\section{SIGNIFICANCE OF THE STUDY}

The results could suggest an obturation technique which provides the best apical seal when using Diadent's DiaPro 0.04 and 0.06 taper gutta percha to obturate canals instrumented with ProFile Series 29, 0.06 taper rotary files.

\section{NULL HYPOTHESES}

The null hypotheses are: 1) There is no significant difference in mean apical linear dye leakage among the four groups. 2) There is no significant difference in the presence of leakage among the four groups. 


\section{DEFINITION OF TERMS}

Actual tooth length - The measured length, from the reference point, of a file placed in the canal until its tip becomes visible at the apical foramen using $2.5 X$ magnification.

Cold lateral condensation - An obturation technique which involves the placement of a sealer in the canal, followed by a measured master gutta percha point, which is laterally condensed by a spreader to make room for additional accessory gutta percha points.

Crown-down technique - A technique of canal instrumentation which enlarges the coronal portion of the canal initially. The canal is enlarged in a step-wise fashion from the coronal orifice towards the apical foramen with progressively smaller files until the desired length is achieved.

Leakage - A qualitative description of the presence of India ink dye coronal to the endpoint of the gutta percha, as visualized microscopically.

Linear apical leakage - A quantitative measurement of the maximum penetration of the dye from the apical endpoint of the master gutta 
percha cone, coronally.

Reference point - A repeatable flat landmark identified at the coronal orifice created when the tooth was sectioned at its cemento-enamel junction.

Rotary instrumentation - A technique of canal instrumentation which utilizes an engine driven handpiece to rotate endodontic files in a $360^{\circ}$ clockwise direction.

Single cone obturation - Obturation of the canal space with a single cone of gutta percha following placement of an endodontic sealer.

Standard preparation - A method of root canal instrumentation which creates an apical preparation with a taper of approximately $0.02 \mathrm{~mm} / \mathrm{mm}$.

Step-back preparation - A method of root canal instrumentation which enlarges the apical extent of the canal in a serial fashion. After working length determination, the apical one third is enlarged until a master apical file is determined. A taper in the apical one third of the canal is then prepared by stepping back one millimeter and one larger file at a time. 
Taper - A descriptive term for the smooth increase in diameter of a conical object from its smallest diameter to its largest diameter.

Touch-N-Heat - An electronic device which provides the delivery of a heated plugger or spreader to the canal.

Warm vertical hybrid technique - A method of obturation which involves the placement of a sealer and a master gutta percha point, followed by cold lateral condensation with a spreader and the placement of two accessory gutta percha points. The gutta percha mass is then heated and condensed vertically with a series of pre-fitted pluggers.

Working length - (WL), The length determined by subtracting $1.0 \mathrm{~mm}$ from the actual tooth length. 


\section{ASSUMPTIONS}

1) The prevention of apical leakage is an important factor in the success of endodontic therapy. 2) An apical dye leakage study is an appropriate indicator of the quality of the apical seal.

\section{LIMITATIONS}

The duplication of in vivo conditions and constraints was not possible. The root canals of extracted teeth were instrumented and obturated on the bench-top to facilitate control of variables. The roots of teeth present many unique morphologic characteristics that could not be controlled. Individual root canal system variability could effect the instrumentation and obturation quality of any given tooth.

\section{DELIMITATIONS}

The extracted teeth were selected carefully in an attempt to minimize variability. Roots containing only one canal and one apical foramen were 
selected. Roots with greater than twenty degrees of curvature in the apical one-third were eliminated. Selected teeth had completely formed apices and any tooth which allowed a \#30 ISO file to pass through the apical foramen was eliminated. Teeth were sectioned at the CEJ to allow optimal straight line access. All instrumentation and obturation was performed by the principal investigator. Roth's 801 endodontic sealer was used in all experimental groups. Sealer was allowed to set for 72 hours in a 100\% humidity environment. Apical leakage was determined after the teeth were suspended in India Ink dye for 72 hours. A clearing method was used to visualize the dye leakage using microscopic examination. Measurement of leakage was done independently by two endodontic residents without knowledge from which experimental group each tooth originated. 


\section{CHAPTER 2}

\section{REVIEW OF LITERATURE}

Ingle and Levine proposed the standardization of endodontic instruments in 1958 (3). Prior to 1958, endodontic instruments had no manufacturing standards, files made by different companies were not consistently sized and no quality control was in place. By 1962 a committee made up of Endodontists from the American Association of Endodontists along with representatives from several manufacturers was formed to develop the standardization of endodontic instruments and materials (4). This group worked with the International Standards Organization (ISO) and in 1976 the the ADA approved the standardization format proposed by ISO for endodontic instruments (5). The ISO system of numbering files is based on the diameter of the tip of the file in hundredths of a millimeter. An ISO 
size \#10 file has a tip diameter, referred to as position $D_{0}$, of $0.10 \mathrm{~mm}$. The next larger file in the ISO system is the \#15 which has a tip diameter of $0.15 \mathrm{~mm}$. Each file in the series increases in tip diameter by $0.05 \mathrm{~mm}$ up through \#60, after which each file increases by $0.10 \mathrm{~mm}$. ISO set the standard taper of endodontic files at $0.02 \mathrm{~mm} / \mathrm{mm}$.

In 1992, Schilder developed and patented a new system of endodontic files, based on a fixed $29 \%$ increase of tip diameter from one file to the next larger file in the series. These files evolved into Tulsa/Dentsply's ProFile Series 29 files. The PRO-29 system offers a more gradual increase in $D_{0}$ diameter at the beginning of the series compared to the ISO system. The current PRO-29 files are nickel-titanium and are available in 0.04 $\mathrm{mm} / \mathrm{mm}$ and $0.06 \mathrm{~mm} / \mathrm{mm}$ taper. The files are available in sizes beginning with $D_{0}$ of $0.129 \mathrm{~mm}$ and increasing by $29 \%$ up to a $D_{0}$ size of $1.0 \mathrm{~mm}$. Instrumentation with files of increased taper provides several advantages to the clinician. The increased taper of the PRO-29 files, allow the operator to widen or enlarge the coronal portion of the canal early 
during instrumentation. Early enlargement of the coronal portion of the canal removes pulpal tissue and microbial irritants and reduces the risk of pushing debris into the periapical tissues (6). Reddy found that rotary instrumentation with the ProFile Series 29 files extruded less debris out the apical foramen than a step-back preparation using hand files (11). Early coronal enlargement also permits irrigants to reach the apex more effectively to maximize killing of bacteria and removal of necrotic debris. Senia showed that standard instrumentation to an ISO \#30 file did not permit sodium hypochlorite irrigant to effectively reach the apical extent of the canal (7). Increased flaring also provides the clinician with increased tactile awareness at the apical third of the canal (6). It also allows for deeper penetration of spreaders and pluggers during obturation of the canal (8). Yared showed that deeper plugger penetration resulted in significantly less apical leakage (9). Allison demonstrated that the most important factor in preventing apical leakage was the depth of the initial spreader penetration. In his study, when the spreader reached within $1.0 \mathrm{~mm}$ of the 
working length, less leakage was observed. He concluded that the shape of the canal preparation significantly effected the quality of the obturation (2). Thompson evaluated the shaping ability of the Profile Series 29 files used in a crown-down fashion and found they produced definite apical stops, smooth canal walls, and good flow and taper (10).

The goal of endodontic therapy is the complete cleaning and shaping of the root canal system, development of a fluid-tight seal at the apical foramen, and total obliteration of the root canal spaces. Complete debridement to remove all toxins is impossible due to the intricacies and complexities present in the canal system (12). Any bacteria or toxins left in the canal must be isolated by obturation so that they cannot reach the periapical tissues. The apical seal must prevent leakage between the root canal and the periapical tissues in order to prevent bacteria from using the available fluid as a substrate (13). The seal obtained during obturation must also be protected from coronal microleakage. Coronal leakage has been found to be a very important factor in endodontic success $(14,15)$. 
There have been many studies evaluating endodontic success and the causes of failure. Swartz reported an overall success rate of $90 \%$ in his study. He evaluated over 1000 teeth, clinically and radiographically, in a twenty year retrospective study. He concluded that overfilled canals were four times more likely to result in failure than canals filled short of the radiographic apex (14). According to Ingle, the most common cause of endodontic failure is apical percolation caused by incomplete obturation. The Washington study showed that $59 \%$ of the endodontic failures in their study were due to incomplete obturation (15). Barbakow found an overall success rate of $87 \%$ with short fills slightly less successful $(76 \%)$ than overfills (82\%) (16). Morse found an overall success rate of $95 \%$ and concluded that flush fills and overfills were more successful than underfills (17).

Although the apical seal is important, the success or failure of endodontic treatment depends to a large degree on the quality of the coronal restoration. Swartz's study reported that endodontic failure 
occurred two times more often when an inadequate coronal restoration was present (14). Ray and Trope determined that the most important factor for endodontic success is not the quality of the endodontic treatment, but the quality of the coronal restoration. They radiographically examined over 1000 teeth which had endodontic therapy and concluded that radiographic evidence of periapical inflammation was present least often when good endodontic therapy and a good restoration was present. Teeth with poor endodontic therapy and a good restoration had less periapical inflammation than did teeth with good endodontic therapy and a poor restoration (18).

The permeability of the apical seal has been demonstrated by dye penetration $(19,20,21)$, radioisotope penetration $(22,23)$, electrochemical (24), microbiological invasion (25), fluorometric (26), and scanning electron microscope examination (27). The penetration of a dye continues to be a commonly used technique to assess the quality of the apical seal. Matloff found that a dye penetrated farther coronally than radioisotopes (28). Several studies have suggested that a vacuum must be applied to remove any 
trapped air inside the canal which could hinder the penetration of a dye $(29,30)$. Kersten and Moorer found that dyes used to evaluate leakage are much smaller particles than bacteria. They summarized that microleakage of small particles is unlikely to play a role in periapical disease but leakage of high molecular weight substances of bacteria-sized particles is an important factor (31). Hovland and Dumsha concluded that all root canal sealers leak to some degree. They believe there is probably a critical level of leakage that is unacceptable for healing, and therefore results in endodontic failure. This leakage may occur at the interface of the dentin and sealer, at the interface of the semi-solid core and sealer, through the sealer itself, or by dissolution of the sealer (32).

Dye penetration has been examined by several methods of visualization. Eldeeb suggested that the longitudinal sectioning of roots would not allow the examiner to measure the leakage accurately and that the examiner will get a false impression of under-penetration unless the plane of sectioning reveals the area of deepest penetration (33). Cross-sectioning of the root 
has been utilized in several leakage studies (34). A disadvantage of this technique is that tooth structure is lost during cutting of the root and measurement of maximum penetration could again be erroneous. Robertson developed a clearing technique which was altered slightly by Roda and Gutmann $(35,36)$. This technique allows the microscopic visualization of dye penetration around the circumference of the canal.

Currently in endodontics, gutta percha is used along with an endodontic sealer to obturate canal systems. The gutta percha acts to fill the large space in the canal and to force the sealer into the intricacies and lateral canals. Diadent's DiaPro 0.04 and 0.06 taper gutta percha cones are a new product developed to respond to the need for gutta percha which matches the size of the PRO-29 files. The taper of the DiaPro gutta percha points matches the taper of the PRO-29 files. Since the cones match the size and taper of the PRO-29 files, they may lend themselves to a more precise adaptation to the walls of the prepared canal. However, the canal system is rarely a perfectly conical shape and irregularities must still be filled by the 
sealer, or by sealer and gutta percha during obturation.

Cold lateral condensation of gutta percha has remained the most widely used obturation technique. Advantages of this technique include its predictability, length control and ease of use. Disadvantages include its inability to produce a homogenous mass, potential voids when accessory cones do not reach the depth of the spreader penetration, and less adaptation to irregularities in the canal system (37). Lateral condensation is often used as a control for evaluating the sealing ability of new obturation techniques (38). Lateral condensation of canals instrumented with the PRO29, 0.06 taper instruments can utilize a master gutta percha cone which is ISO sized. However, the apical preparation should be created with an ISO hand file in order to accept the corresponding ISO sized master gutta percha cone. Obturation of canals prepared with PRO-29 files could also utilize a DiaPro master gutta percha cone that matches the size of the master PRO-29 file and has a greater taper than an ISO gutta percha point. The Dia-Pro gutta percha cones would require the placement of fewer 
accessory cones since they would occupy more of the prepared canal space. The operator would choose between a DiaPro 0.04 or 0.06 taper master gutta percha cone. Use of a 0.04 taper master gutta percha cone would allow the initial spreader to reach within $1.0 \mathrm{~mm}$ of working length. Selection of a 0.06 taper master gutta percha cone would not allow the initial spreader to reach within $1.0 \mathrm{~mm}$ of the working length, which could lead to increased apical leakage (2).

The tapered funnel-form preparation produced by the PRO-29 files is an ideal preparation for warm vertical condensation of gutta percha (39). Warm condensation produces a homogenous mass which conforms to the irregularities of the canal space. Gutta percha is often pushed into lateral and accessory canals with this technique (40). Warm compaction results in less force being exerted on the roots than cold lateral condensation (41). The disadvantage of this method is that it is more technique-sensitive. The use of DiaPro gutta percha cones could provide the operator with a precisely fitted master gutta percha cone. Warm vertical condensation pressures 
could wedge the DiaPro gutta percha point into the prepared canal so that a fluid-tight seal could be created apically.

Many clinicians might be tempted to create a canal preparation with the PRO-29 files and obturate with a single DiaPro cone which matches the size and taper of the master PRO-29 file. Some studies have shown no significant difference in leakage when a single cone technique was compared to cold lateral condensation. Narracott found that a single cone dipped in chloroform produced as good a seal as lateral condensation in an in vitro study (42). Zidan obturated canals with a single cone and dentin bonding agents. He instrumented canals to an ISO \#45 and created no step-back flare. He found no significant difference in mean linear dye leakage between single cone and lateral condensation groups (43). Dalat found no significant difference in leakage in an in vitro dye study between roots obturated with a single cone and laterally condensed groups (44). Beatty examined the shape of the preparation and its effects on the apical seal when single cones were used to obturate the canals. He found that a step- 
back preparation and lateral condensation allowed less linear apical dye leakage than either a standard or a step-back preparation when a single cone obturation was accomplished (45).

This study will examine the use of Diadent's DiaPro gutta percha points with different obturation techniques. The unique size and taper of the DiaPro gutta percha points could benefit the clinician in the following wasys: 1) Provide a precisely fit master gutta percha point with respect to tip size and taper; 2) Simplify obturation because less accessory points are required when using cold lateral condensation compared to ISO gutta percha points; 3) Improve obturation with warm vertical condensation because it would provide a well fitted master gutta percha point and a larger mass of gutta percha to warm and condense than an ISO size master gutta percha point does; 4) Provide a reliable single cone obturation technique. 
CHAPTER 3

METHODS AND MATERIALS

\section{SAMPLE DESCRIPTION}

Recently extracted teeth were collected from the West Virginia University School of Dentistry Oral \& Maxillofacial Surgery Department and stored in formalin. An attempt was made to reduce some variability among the samples by eliminating any tooth with greater than twenty degrees of root curvature in the apical one-third. Only roots with one canal and one apical foramen were selected. Any tooth that allowed an ISO size \#30 file to slip passively through its apical foramen was eliminated to minimize variability in root canal size. In addition, if an ISO size \#10 file could not pass through the apical foramen the tooth was eliminated. An Expedited Review from the Institutional Review Board for the Protection of Human Research Subjects was received since the teeth were extracted by the Oral Surgeons prior to the commencement of this study. 


\section{RESEARCH DESIGN}

This study will compare apical dye leakage of four experimental groups.

Leakage will be evaluated microscopically after the roots are rendered transparent using a clearing process first published by Robertson (35).

Please refer to Table 1 for a summary of the experimental groups.

Table 1. Summary Table of Experimental Groups

\begin{tabular}{|c|c|c|c|c|}
\hline $\begin{array}{c}\text { 亏े } \\
\text { डे }\end{array}$ & $\begin{array}{c}\text { Rotary } \\
\text { Instrumentation } \\
\text { Length }\end{array}$ & $\begin{array}{c}\text { Apical } \\
\text { Preparation }\end{array}$ & $\begin{array}{c}\text { Taper of Master } \\
\text { Gutta Percha } \\
\text { Cone }\end{array}$ & $\begin{array}{c}\text { Obturation } \\
\text { Technique }\end{array}$ \\
\hline 1 & $\begin{array}{c}2.0 \mathrm{~mm} \text { short } \\
\text { of WL }\end{array}$ & ISO 0.02 taper & ISO 0.02 taper & $\begin{array}{c}\text { Cold } \\
\text { Lateral }\end{array}$ \\
\hline 2 & to WL & $\begin{array}{c}\text { PRO-29 } 0.06 \\
\text { taper }\end{array}$ & $\begin{array}{c}\text { Dia-Pro } 0.04 \\
\text { taper }\end{array}$ & $\begin{array}{c}\text { Cold } \\
\text { Lateral }\end{array}$ \\
\hline 3 & to WL & $\begin{array}{c}\text { PRO-29 } 0.06 \\
\text { taper }\end{array}$ & $\begin{array}{c}\text { Dia-Pro } 0.06 \\
\text { taper }\end{array}$ & $\begin{array}{c}\text { Warm } \\
\text { Vertical } \\
\text { Hybrid }\end{array}$ \\
\hline 4 & to WL & $\begin{array}{c}\text { PRO-29 } 0.06 \\
\text { taper }\end{array}$ & $\begin{array}{c}\text { Dia-Pro } 0.06 \\
\text { taper }\end{array}$ & Single Cone \\
\hline
\end{tabular}




\section{INSTRUMENTATION METHODOLOGY}

The teeth were placed in $2.5 \%$ sodium hypochlorite for 24 hours prior to instrumentation to dissolve tissue from the root surfaces. The roots were scaled to remove all remaining tissue. Each tooth was sectioned horizontally at a point just apical to the cemento-enamel junction with a high speed fissure bur, cooled with water. Single rooted teeth were explored and examined using 2.5X magnification to ensure that selected teeth had only one canal and one apical foramen. Mandibular molars were sectioned at the furcation to acquire the distal roots. Only mandibular molar roots with a single canal and apical foramen were selected. Palatal roots of maxillary molars were obtained in a similar fashion. All selected teeth were explored with an ISO \#10 to ensure that the canal was patent from coronal orifice through the apical foramen. Any root that allowed an ISO \#30 file to pass unrestricted through its apical foramen was eliminated. Sixty-eight roots 
were selected and randomly assigned to four experimental groups of sixteen samples per group. Two roots served as positive controls and two as negative controls.

A standard initial instrumentation procedure was carried out with all roots. Actual tooth length was determined by inserting an ISO \#10 file in the canal. The length of the file from the reference point was measured when the tip of the file became visible at the apical foramen using $2.5 \mathrm{X}$ magnification. The working length was determined and recorded by subtracting $1.0 \mathrm{~mm}$ from the measured actual tooth length. The canal was instrumented with ISO hand files from \#10 through \#20 at working length. Gates glidden burs \#2 through \#4 were used to enlarge the coronal half of the canal. Irrigation with $3.0 \mathrm{ml}$ of $5.25 \%$ sodium hypochlorite was used for each root during this process. The teeth were then individually stored in biopsy jars containing formalin until further instrumentation was performed. 
EXPERIMENTAL GROUP 1. Preparation of the canal consisted of rotary instrumentation with PRO-29, 0.06 taper at $150 \mathrm{rpm}$ using a crown-down technique. RC Prep was used as a canal lubricant. The tooth was held in a moist cotton 2X2 during instrumentation. Crown-down instrumentation was initiated with the \#8 PRO-29 file $\left(D_{0}=0.600 \mathrm{~mm}\right)$, followed by the \#7 $\left(D_{0}=0.465 \mathrm{~mm}\right), \# 6\left(D_{0}=0.360 \mathrm{~mm}\right)$ and $\# 5\left(D_{0}=0.279 \mathrm{~mm}\right)$ and was continued until one of the PRO-29 files reached a point $2.0 \mathrm{~mm}$ short of the working length. The last PRO-29 used was the one which did not have to be forced to reach the desired length as determined by the operator using clinical experience as a guide. The apical $2.0 \mathrm{~mm}$ of the canal was then enlarged with ISO hand files until the master apical file created a solid seat. Irrigation with $3.0 \mathrm{ml}$ of $5.25 \%$ sodium hypochlorite was used for each root during this process. The canal was dried with the appropriate size paper points and patency was confirmed by passing an ISO \#10 file through the apical foramen. Roth's sealer was placed in the canal using the master apical file. An ISO sized master gutta percha point was selected which matched 
the size of the ISO master apical file. Cold lateral condensation was performed with a medium-fine size nickel-titanium finger spreader and fine accessory gutta perch cones. The number of times that the spreader was able to reach within $1.0 \mathrm{~mm}$ of the working length was recorded. The obturation was considered complete when the spreader could not reach within $6 \mathrm{~mm}$ of the working length. The gutta percha was cut at the orifice using a Touch-n-Heat and an appropriate sized plugger was then used to push apically on the gutta percha. The orifice was cleaned of sealer with a cotton pellet moistened with alcohol. Cavit was placed in the coronal access and the tooth was placed into its container with a moist $2 \times 2$. The sealer was allowed to set in this environment for 72 hours.

EXPERIMENTAL GROUP 2. Preparation of the canal consisted of rotary instrumentation with PRO-29, 0.06 taper at 150 rpm using a crown-down technique. RC Prep was used as a canal lubricant. The tooth was held in a moist cotton $2 \times 2$ during instrumentation. Crown-down instrumentation was 
performed as in group 1. However, rotary instrumentation was continued until the file reached the full working length. The last PRO-29 used was the one which did not have to be forced to reach the desired length as determined by the operator using clinical experience as a guide.

Irrigation with $3.0 \mathrm{ml}$ of $5.25 \%$ sodium hypochlorite was used for each root during this process. The canal was dried with the appropriate size paper points and patency was confirmed by passing an ISO \#10 file through the apical foramen. Roth's sealer was placed in the canal using an ISO \#25 file. A DiaPro 0.04 taper master gutta percha point was selected that matched the size of the master apical PRO-29 file. It was coated with sealer and placed in the canal to working length. Cold lateral condensation was performed with a medium-fine size nickel-titanium finger spreader and fine accessory gutta perch points. The number of times that the spreader was able to reach within $1.0 \mathrm{~mm}$ of the working length was recorded. The obturation was considered complete when the spreader could not reach within $6 \mathrm{~mm}$ of the working length. The gutta percha was cut at the orifice 
using a Touch-n-Heat and an appropriate size plugger was then used to push apically on the gutta percha. The orifice was cleaned of sealer with a cotton pellet moistened with alcohol. Cavit was placed in the coronal access and the tooth was placed into its container with a moist $2 \times 2$. The sealer was allowed to set in this environment for 72 hours.

EXPERIMENTAL GROUP 3. Preparation of the canal was done in the same manner as experimental group 2. The canal was dried with the appropriate size paper points and patency was confirmed by passing an ISO \#10 file through the apical foramen. A sequence of pre-fitted Schilder pluggers were selected and measured so that they would not contact the canal walls at the measured depths. Roth's sealer was placed in the canal using an ISO \#25 file. A DiaPro 0.06 taper master gutta percha cone was selected which matched the size of the master apical PRO-29 file. It was coated with sealer and placed in the canal to working length. Two accessory cones were added using cold lateral condensation. Warm vertical 
condensation was used to obturate the canal in the following manner: $A$ Touch-n-Heat unit was set at a power setting of 7 and a spreader-type heat delivery tip was used. The excess gutta percha was seared off at the orifice and the largest pre-fitted Schilder plugger was used to condense the gutta percha 1 to $2 \mathrm{~mm}$ into the canal. The hot Touch-n-heat tip was inserted $2 \mathrm{~mm}$ into the gutta percha and the next smaller Schilder plugger was used to condense again. The sequence of heating the coronal $2.0 \mathrm{~mm}$ of gutta percha and condensing with the next smaller pre-fitted Schilder was continued until only the apical $5.0 \mathrm{~mm}$ of gutta percha remained in the canal. Back-fill was completed with an Obtura II in a step-wise fashion, condensing with the same pre-fitted Schilder pluggers until the canal was completely obturated. The orifice was cleaned of sealer with a cotton pellet moistened with alcohol. Cavit was placed in the coronal access and the tooth was placed into its container with a moist $2 \times 2$. The sealer was allowed to set in this environment for 72 hours. 
EXPERIMENTAL GROUP 4. Preparation of the canal was done in the same manner as experimental group 2. The canal was dried with the appropriate size paper points and patency was confirmed by passing an ISO \#10 file through the apical foramen. Roth's sealer was placed in the canal using an ISO \#25 file. A DiaPro 0.06 taper master gutta percha cone was selected that matched the size of the master apical PRO-29 file. It was coated with sealer and placed in the canal to working length. The gutta percha was cut at the orifice using a Touch-n-Heat and an appropriate size plugger was then used to push apically on the gutta percha. The orifice was cleaned of sealer with a cotton pellet moistened with alcohol. Cavit was placed in the coronal access and the tooth was placed into its container with a moist $2 \times 2$. The sealer was allowed to set in this environment for 72 hours.

POSITIVE CONTROL. Preparation of the canal was done in the same manner as experimental group 2. The canal was dried with the appropriate size paper points and patency was confirmed by passing an ISO \#10 file 
through the apical foramen. A Dia-Pro 0.06 taper master gutta percha cone that matched the size of the master apical PRO-29 file was placed in the canal without any sealer. The gutta percha was cut at the orifice using a Touch-n-Heat. The orifice was cleaned of sealer with a cotton pellet moistened with alcohol, and Cavit was placed in the access cavity.

NEGATIVE CONTROL. Preparation of the canal was done in the same manner as experimental group 2. The canal was dried with the appropriate size paper points and patency was confirmed by passing an ISO \#10 file through the apical foramen. Roth's sealer was placed in the canal using an ISO \#25 file. A DiaPro 0.04 taper master gutta percha cone was selected which matched the size of the master apical PRO-29 file. It was coated with sealer and placed in the canal to working length. Cold lateral condensation was performed with a medium-fine size nickel-titanium finger spreader and fine accessory gutta perch cones. The obturation was considered complete when the spreader could not reach within $6 \mathrm{~mm}$ of the 
working length. The gutta percha was cut at the orifice using a Touch-nHeat and an appropriate size plugger was then used to push apically on the gutta percha. The orifice was cleaned of sealer with a cotton pellet moistened with alcohol. Cavit was placed in the coronal access and the tooth was placed into its container with a moist $2 \times 2$. The sealer was allowed to set in this environment for 72 hours.

\section{LEAKAGE METHODOLOGY}

The experimental roots were air dried and coated with two coats of nail polish so that only the apical $3.0 \mathrm{~mm}$ of root was not covered. The negative control roots were completely covered with two coats of nail polish including the apical foramen. The positive control roots were coated with two coats of nail polish so that only the apical $3.0 \mathrm{~mm}$ of root was not covered. After air drying, each tooth was returned to its container until the dye process could be carried out later that day. 
The roots were suspended vertically in their individual containers by attaching them to the container wall with red rope wax. The wax was placed in the coronal one-third of the root so that it did not contact the portion of the root that was not covered with nail polish. The root was positioned so that the apex did not contact the wall or bottom of the container. India Ink was placed into each container so that one half of the root was covered. The containers were placed into a vacuum desiccator and a vacuum of 695 torr was applied for fifteen minutes. The vacuum was turned off and the teeth were allowed to sit in the dye for 72 hours. They were rinsed with tap water and the nail polish was removed with a scaler. After placing them back in their individual containers, $5 \%$ nitric acid was added to decalcify the roots over the next 24 hours. The roots were rinsed with tap water and dehydrated by placing $80 \%$ ethyl alcohol in the containers for 24 hours followed by 24 hours in $100 \%$ ethyl alcohol. Clearing of the roots was accomplished by placing methyl salicylate in the containers so that the root was completely covered by the liquid. The roots became transparent 
shortly after the methyl salicylate was added to the containers. The roots were stored in the containers with the methyl salicylate until they could be evaluated for dye leakage two days later. Each container was covered with tape so that the investigators could not identify which group the tooth belonged to and each tooth was given an identification number.

\section{DATA COLLECTION}

Two endodontic residents independently evaluated leakage using a 10X magnification intraoral microscope. Quantitative evaluation involved the measurement of linear apical leakage of the dye, using a boley gauge under magnification, coronal to the endpoint of the gutta percha. Each investigator recorded the measurement on a data collection sheet as shown in Appendices A and B. The measurements were averaged for each tooth to determine a linear leakage value per tooth. Qualitative determination of leakage involved determining if no leakage was present. A measurement of $0.0 \mathrm{~mm}$ indicated no leakage coronal to the endpoint of the gutta percha. 
Appendix $C$ provides the data collected during the instrumentation and obturation process. The working length, master apical file tip diameter, and the number of spreaders that reached within one millimeter of the working length were recorded.

\section{STATISTICAL ANALYSIS}

The experimental group results were analyzed using two statistical tests. First, the leakage was analyzed qualitatively by determining the number of roots per group which showed leakage using a Chi Square analysis. Second, the quantitative measurements of linear apical leakage were analyzed using the Kruskal-Wallis rank sums test.

The number of spreaders that reached within $1.0 \mathrm{~mm}$ from working length in group 1, 2 and 3 were statistically analyzed using ANOVA. 


\section{EQUIPMENT AND MATERIALS}

The following is a list of materials and equipment used in this study:

68 extracted human teeth

Standard School of Dentistry Endodontic Set Up

Tycom Quantec-E rotary handpiece (Tycom, Irvine, CA)

ProFile Series 29, 0.06 taper rotary files (Tulsa Dental, Tulsa, OK)

Sureflex ISO endodontic files (Dentsply, Milford, DE)

$5.25 \%$ Sodium Hypochlorite (The Clorox Company, Oakland, CA)

RC Prep (Premier, Norristown, NJ)

Endodontic Irrigation Syringe (Monoject, Sherwood Medical, St. Louis, MO)

Diadent Dia-Pro -.04 taper Absorbent Paper Points (Diadent Group International, Burnaby, B.C. Canada)

Diadent Dia-Pro -.04 and -.06 taper Gutta Percha Points (Diadent Group International, Burnaby, B.C. Canada) 
ISO sized gutta percha points (Dentsply International Inc., Milford, DE)

Enamel nail polish (Revlon Inc, NY, NY)

Schilder Pluggers (Dentsply International Inc, Milford, DE)

Touch-N-Heat (Analytic Technology, Redmond, WA)

Roth Root Canal Cement (Type 801 Elite grade, Roth International, Chicago, IL)

Nickel-Titanium Finger Spreader (Hyflex, The Hygenic Corporation, Akron, $\mathrm{OH})$

Cavit (ESPE, Germany)

Fixation Solution, a 10\% neutral buffered Formalin Solution (Hydrol Chemical Company, Yeadon, PA)

Nitric Acid (VWR Scientific Products, West Chester, PA)

Ethyl Alcohol (Fisher Scientific, Fair Lawn, NJ)

Higgins India Ink (Faber-Castell Corporation, Lewisburg, TN)

Methyl Salicylate (JT Baker, Phillipsburg, NJ)

Global Intraoral Microscope (Global Surgical Corporation, St. Louis, MO) 
Boley Gauge (William Dixon, Carlstadt, NJ)

Vacuum Desiccator

Vacuum gauge

Gates Glidden Burs (Dentsply, Milford, DE)

Obtura II (Obtura Corporation, Fenton, MO) 
CHAPTER 4

\section{RESULTS AND DISCUSSION}

\section{RESULTS}

The results of this study supported both of the null hypotheses. Figure 1 provides the number of roots in each group which showed apical leakage. Approximately $25 \%$ of each group showed the presence of leakage. There were no statistically significant differences among the groups for the presence of leakage (Chi Square, $\mathrm{p}=0.94$ ).

Figure 2 provides the mean linear apical leakage per experimental group. There was no significant difference found between the groups for mean linear apical leakage (Kruskall-Wallis, $\mathrm{p}=0.94$ ). 
Table 2 shows the mean apical leakage for each experimental group. Group

4, single cone obturation group, had the greatest linear apical leakage.

Group 3, warm vertical condensation showed the least linear apical leakage.

Mean leakage values for cold lateral condensation with either ISO size or

Diadent DiaPro 0.04 taper gutta percha were nearly equivalent.

Table 2. Linear Apical Leakage Data

\begin{tabular}{|c|c|c|c|}
\hline Group & $\begin{array}{c}\text { Sample } \\
\text { Size }\end{array}$ & Mean Apical & Standard \\
\hline 1 & 16 & 0.17 & Error \\
\hline 2 & 15 & 0.15 & 0.12 \\
\hline 3 & 15 & 0.09 & 0.12 \\
\hline 4 & 16 & 0.30 & 0.12 \\
\hline
\end{tabular}


The results of the control teeth supported the research design. The two positive controls showed complete dye penetration and the two negative controls showed no dye penetration.

Table 3 shows the mean number of spreaders that reached within 1.0 $\mathrm{mm}$ from working length in groups 1,2 and 3. Statistically significant difference in the number of spreaders was found between group 3 and groups 1 and 2 ( $p<0.0001)$. 
Table 3. Mean Number of Spreaders Within $1.0 \mathrm{~mm}$ of Working Length

\begin{tabular}{|c|c|c|c|}
\hline Group & Sample Size & $\begin{array}{c}\text { Mean \# of } \\
\text { Spreader } \\
\text { Penetrations }\end{array}$ & $\begin{array}{c}\text { Standard } \\
\text { Error }\end{array}$ \\
\hline 1 & 16 & 2.4 & 0.23 \\
\hline 2 & 15 & 2.5 & 0.23 \\
\hline 3 & 15 & 0.5 & 0.23 \\
\hline
\end{tabular}




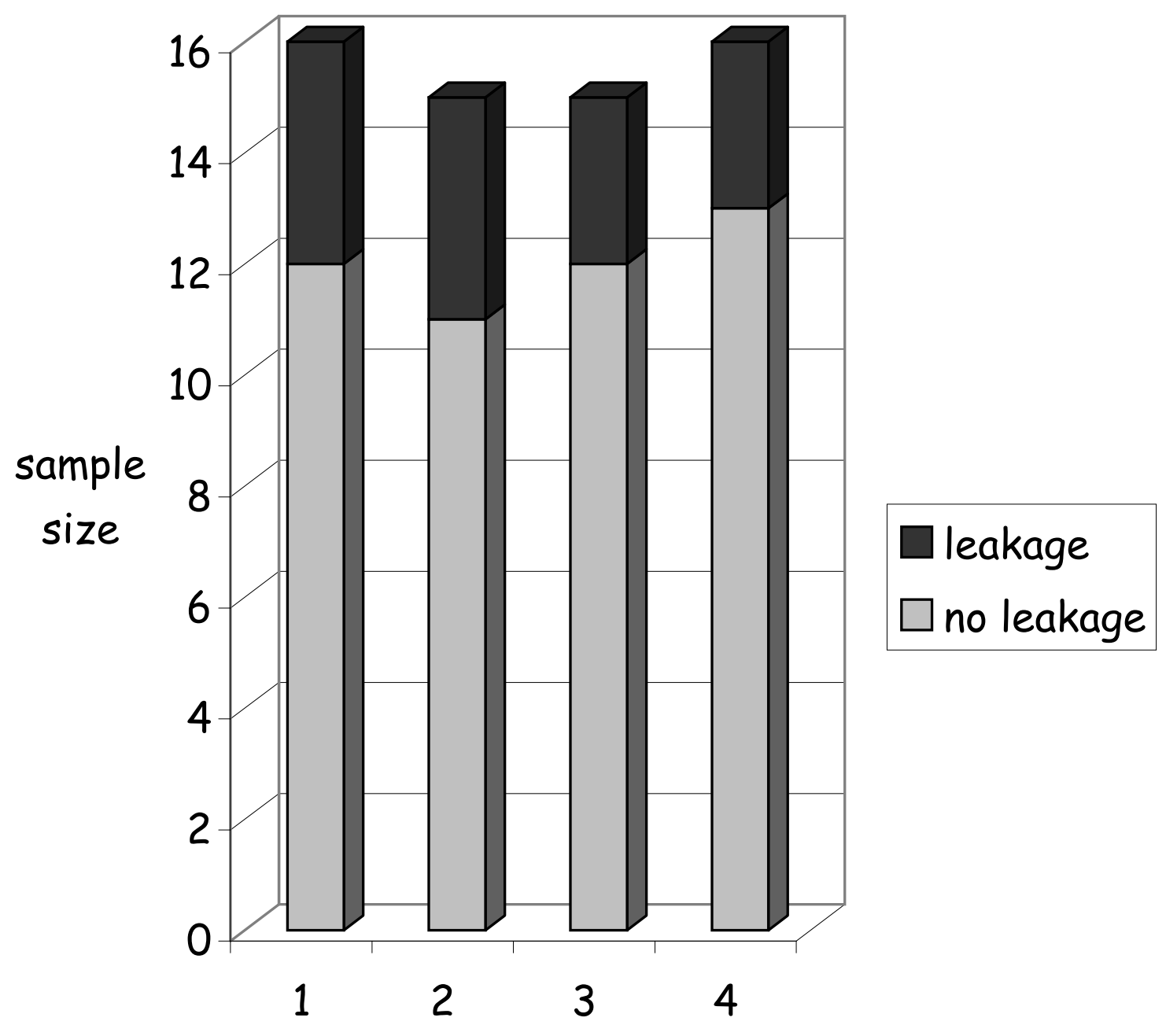

Experimental Groups

Figure 1. Presence of Leakage 


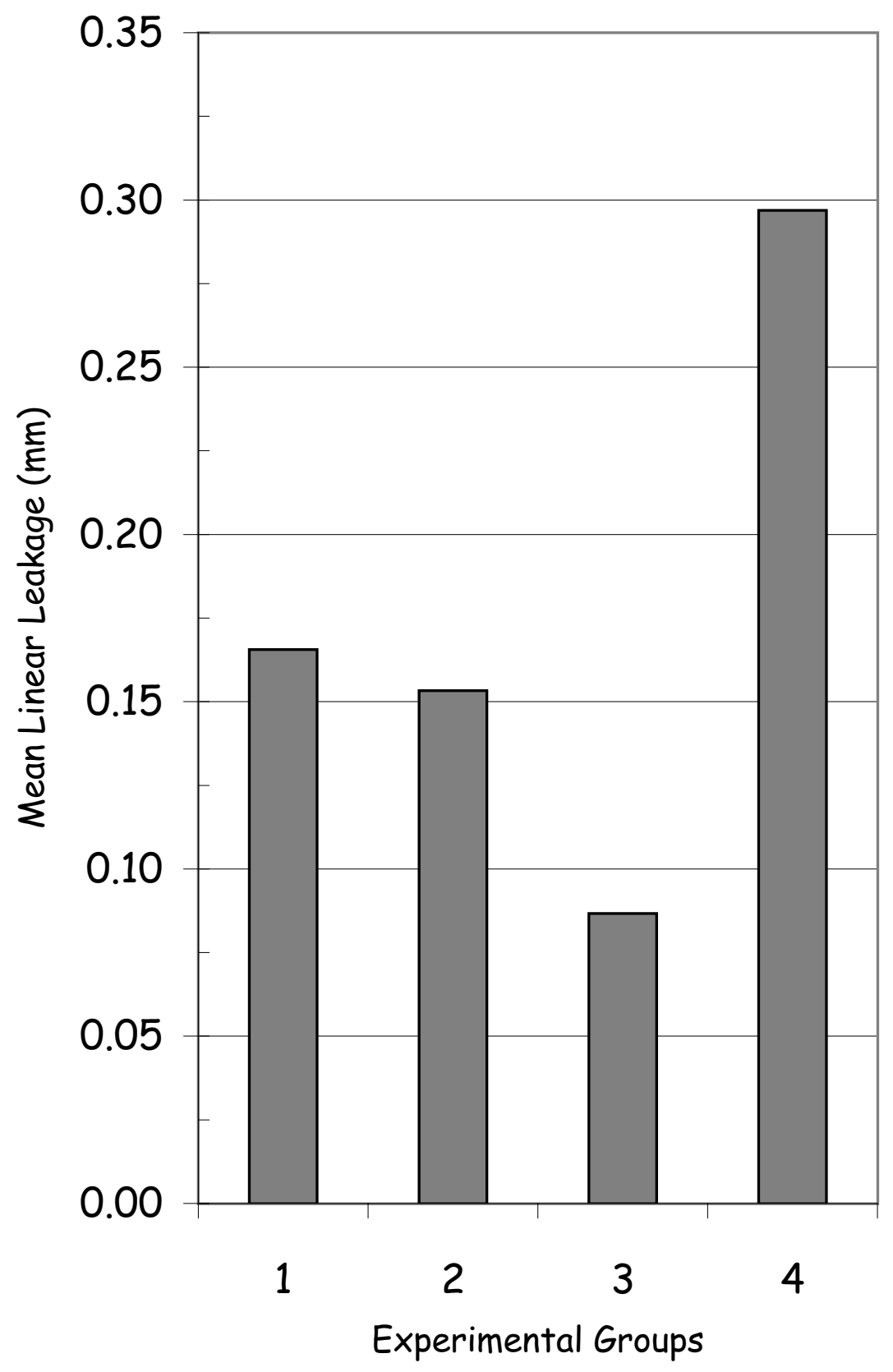

Figure 2. Mean Linear Apical Leakage 


\section{DISCUSSION}

The goal of endodontic therapy is the complete cleaning and shaping of the root canal system, development of a fluid-tight seal at the apical foramen, and total obturation of the root canal system. The apical seal must prevent leakage between the root canal and the periapical tissues in order to prevent bacteria from using the available fluid as a substrate (13).

Cleaning of the root canal system is a critical factor in root canal therapy. Chemo-mechanical instrumentation involves bacterial killing, tissue dissolution and flushing away of canal debris by the action of the chemical irrigant. Mechanical instrumentation with files provides mechanical removal of bacteria, toxins, dentin and debris. Instrumentation in the presence of an antibacterial irrigant such as sodium hypochlorite increases the duration of the irrigant's action. Instrumentation with 0.06 taper PRO-29 files removes a generous amount of dentin as the walls of the canal are planed. As the dentin is removed, so are the toxic contents of the canal. Each unique canal must have an ideal preparation size that maximizes the cleaning of that 
canal. However, over-enlargement of the canal undoubtedly weakens the long term strength of the tooth. Many clinicians feel that the 0.06 taper PRO-29 files over-enlarge the canal. Certainly there is a balance that exists between thorough canal cleaning and over-enlargement. The importance of the copious use of a bactericidal irrigant is critical regardless of taper of the files chosen to instrument the canal. The results of this study suggest that thorough chemo-mechanical cleaning of the root canals was accomplished since very little leakage occurred in any experimental group.

The sample roots in this study were chosen to reduce the variables often seen in clinical situations. The samples included the roots of molar, bicuspid and anterior teeth. This was done to provide a group of teeth which reflected the different canal sizes and shapes which we treat in our daily practice. Cleaning and shaping of the roots was straightforward and did not involve much curvature or many canals that were calcified. The apices were patent and yet were not affected by any resorptive process which can make endodontic therapy more challenging. Access to the canals and determination 
of the working length was ideal.

Lateral condensation of canals prepared with PRO-29 files to a 0.06 taper showed no difference in apical leakage when either an ISO 0.02 taper or DiaPro 0.04 taper master gutta percha point was used. Some clinicians feel more comfortable instrumenting the apical preparation with hand files instead of the rotary files. They rely on the rotary files to create a tapered preparation and hand files to provide control during the preparation of the apical one to two millimeters of the canal. Instrumentation of the apical seat with an ISO sized file permits the use of an ISO sized master gutta percha point. Experimental group 1 provided an analysis of this technique and served as the standard of comparison for the other experimental groups.

Spreader penetration to within one millimeter of working length was found to be a critical factor in preventing apical leakage by Allison when he compared standard and step-back preparations (2). He observed that the taper of the root canal preparation directly affects the depth that the spreader can penetrate into the canal. The 0.06 taper of the PRO-29 files 
provides adequate space to allow spreader penetration. However, a larger taper gutta percha point could make it more difficult for a spreader to penetrate apically. This was observed in group 3 when a DiaPro 0.06 taper master gutta percha point did not consistently allow spreader penetration to within $1.0 \mathrm{~mm}$ of working length. However, spreader penetration was no different between the ISO master gutta percha group (group 1) and the DiaPro 0.04 taper master gutta percha group (group 2). A clinician who prefers cold lateral condensation, and desires to reach to within $1.0 \mathrm{~mm}$ of working length with the initial spreader, could choose a Diadent DiaPro 0.04 taper master gutta percha point over an ISO size gutta percha point. Both permitted the spreader to penetrate to within $1.0 \mathrm{~mm}$ from working length and there was no difference in apical dye leakage between them. Selection of the DiaPro 0.04 taper master point has the perceived benefits of reducing obturation time and reducing the likelihood of spreader voids since less accessory points are required.

This study suggests that spreader penetration to within $1.0 \mathrm{~mm}$ of $W L$ is 
not critical to preventing apical leakage. The root canals of experimental group 4 were obturated with single gutta percha point and spreaders were not used at all. Leakage was no different statistically between group 4 and the cold lateral condensation groups. The findings of this study agree with the results of Dalat who found no significant difference in a dye leakage study between single cone and lateral condensation groups. (44) Obturation with a single cone may provide a good quality apical seal if the canal is enlarged sufficiently and the gutta percha point matches the size and taper of the prepared canal precisely. However, obturation with a single gutta percha point does not provide a dense fill at the coronal extent of the canal. Lateral condensation and placement of additional gutta percha points in the coronal half of the canal would improve the density of the obturation there. This is important since complete obturation of the canal is one of the goals of endodontic therapy.

Warm vertical condensation was shown to be effective in providing a good apical seal when the DiaPro 0.06 taper master gutta percha point was 
used. Two accessory points were added using cold lateral condensation prior to the warm vertical condensation. This is referred to as a warm vertical hybrid technique and it keeps the master gutta percha cone from dislodging coronally during condensation. The initial spreader penetration in the warm vertical hybrid group reached within 1.0 of working length an average of only 0.5 times per root, which was significantly less than group 1 or group 2 . It is clear that the use of a 0.06 taper master gutta percha point in a 0.06 taper preparation does not permit the spreader to penetrate within $1.0 \mathrm{~mm}$ from working length consistently. This may not be as important when the master gutta percha point matches the size and taper of the apical half of the canal preparation. Warm vertical condensation using a DiaPro .06 taper gutta percha point to obturate canals instrumented with the PRO-29, 0.06 taper files seems to be an ideal combination. The precise fit and the increased mass of gutta percha enables the operator to very effectively condense and completely fill the canal spaces. Microscopic examination of the obturated roots revealed a homogenous mass of gutta percha which extended into the 
intricacies of the canal system.

Attaining a fluid-tight apical seal has always been considered a critical factor to the success of endodontic therapy. The penetration of a dye continues to be a commonly used technique to assess the quality of the apical seal. In vitro dye studies are often criticized because a large number of them have been done and the results are often conflicting. There are many variables involved in such studies and these variables are often not duplicated. However, in vitro leakage studies are advantageous because they eliminate many of the clinical variables and difficulties faced by the clinician. Standardization of leakage study designs would do much to reduce the criticism pointed at them.

In this study, Diadent's DiaPro gutta percha points were found to produce a good quality apical seal with each of the obturation techniques compared. This seal was equally as effective as that obtained using an ISO size master gutta percha point. Although the clinician should examine many studies and rely on clinically proven methods before choosing one technique 
or material over another, it seems logical to place value in a technique or material which has been shown to provide a good apical seal in-vitro. Further studies may be necessary to evaluate the in vivo success of cases which have been obturated with DiaPro gutta perch points.

Studies by Trope and Swartz have concluded that the quality of the coronal seal is just as important to the outcome of endodontic therapy as the apical seal $(14,15)$. The apical seal may be a temporary seal against invading microorganisms since the sealers commonly used can dissolve over time. Regardless of which obturation technique is employed, the coronal seal must maintain the seal of the root canal that was achieved during endodontic therapy to permit endodontic success to occur. 
CHAPTER 5

SUMMARY AND CONCLUSIONS

\section{SUMMARY}

The prevention of apical leakage is an important factor in the success of endodontic therapy. Obturation of the canal system should provide a fluidtight apical seal. The purpose of this study was to evaluate the apical seal provided by a new gutta percha product (Diadent DiaPro .04 and .06 taper gutta percha points), using four different obturation techniques.

It was hypothesized that there is no difference in mean apical leakage among the four experimental groups. In addition, it was hypothesized that there is no difference in the presence of apical leakage among the four groups.

Sixty eight canals of extracted human teeth were instrumented with ProFile Series 29, 0.06 taper rotary files. They were obturated by four techniques: 1) Cold lateral condensation using an ISO size master gutta 
percha point which matched the size of an ISO master apical file used to prepare the apical $2.0 \mathrm{~mm}, 2$ ) Cold lateral condensation using a DiaPro 0.04 taper master gutta percha point, 3) Warm vertical condensation using a DiaPro 0.06 taper master gutta percha point, 4) Single cone obturation using a DiaPro 0.06 taper master gutta percha point. The teeth were placed in a vacuum and suspended in dye for 72 hours. They were cleared and leakage was measured using a stereomicroscope. The presence of leakage and the mean apical leakage for each experimental group was compared. The results of the study supported both of the null hypotheses.

\section{CONCLUSIONS}

No experimental group proved to be superior in providing an apical seal. This in vitro study supports the use of the Diadent DiaPro 0.04 and 0.06 taper gutta percha points to obturate canals instrumented with the ProFile Series 29, 0.06 taper rotary files. Cold lateral condensation, warm vertical condensation and single cone obturation using the DiaPro gutta percha points 
provided an apical seal which was not statistically different from cold lateral condensation using an ISO sized master gutta percha point. 


\section{REFERENCES}

1. Weine, FS. Endodontic Therapy. Fifth ed., St. Louis: Mosby, 1996. 2-3.

2. Allison, $D A$, et al. The influence of the method of canal preparation on the quality of apical and coronal obturation. J Endodon 1979; 5:298304.

3. Ingle, $J I$, Levine, $M$. The need for uniformity of endodontic instruments, equipment and filling materials Transactions of the $2^{\text {nd }}$ International Conference of Endodontics. Philadelphia, PA, June 1958.

4. Ingle, J I, Bakland LK. Endodontics. Fourth ed., Philadelphia: Lea and Febiger, 1994. 158-159.

5. Council of Dental Materials and Devices. New American Dental Association specification No. 28 for endodontic files and reamers. J Am Dent Assoc 1976 ; 93:813.

6. Cohen, S, Burns RC. Pathways of the Pulp. 6th ed. St. Louis: Mosby, 1994.

7. Senia, ES, Marshall, JF, Rosen, S. The solvent action of sodium hypochlorite on pulp tissue of extracted teeth. Oral Surg Oral Med Oral Path 1971; 31:96-103.

8. Weine, FS. The use of non-ISO-tapered instruments for canal flaring. Compendium 1996; 17:651-663. 
9. Yared, GM, Bou Dagher, FE. Influence of plugger penetration on the sealing ability of vertical condensation. J Endodon 1995; 21:152-3.

10. Thompson, SA, Dummer, PMH. Shaping ability of ProFile .04 Taper Series 29 rotary nickel-titanium instruments in simulated root canals. Part I. Int Endo Jrnl 1997; 30:1-7.

11. Reddy, SA, Hicks, ML. Apical extrusion of debris using two hand and two rotary instrumentation techniques. J Endodon 1998:24:180-3.

12. Davis MS, et al. Periapical and intracranial healing following incomplete root canal fillings in dogs. Oral Surg Oral Med Oral Path 1971:31:662-75.

13. Sjogren $U$, Sundqvist $G$. Bacteriological evaluation of ultrasonic root canal instrumentation. Oral Surg Oral Med Oral Path 1987;63:366-70.

14. Swartz, $D B$, et al. Twenty years of endodontic success and failure $J$ Endodon 1983:9: 198-202.

15. Ingle, JI. Existos y Francasos en Endodoncia. Revista de la Asociacion Odontologica Argentina. 1962:2:50:67.

16. Barbakow $\mathrm{FH}$, et al. An evaluation of 566 cases of root canal therapy in general dental practice.2. postoperative observations. J Endodon 1980; 6:485-89.

17. Morse DR, et al. A radiographic evaluation of the periapical status of teeth treated by the gutta-percha-eucapercha endodontic method: a one-year follow-up study of 458 root canals. Part III. Oral Surg Oral Med Oral Path 1983; 56:190-7. 
18. Ray, HA, Trope, M. Periapical status of endodontically treated teeth in relation to the technical quality of the root filling and the coronal restoration. Int Endo Jrnl 1995; 28:12-18.

19. Beatty, $R G$, et al. The efficacy of four root canal obturation techniques in preventing apical dye penetration. J Am Dent Assoc 1989;119:633-7.

20. Brown, RC, Jackson, CR, Skidmore, AE. An evaluation of apical leakage of a glass ionomer root canal sealer. J Endodon 1994; 20:288-91.

21. Goodell, $G G$, et al. Linear dye penetration of a calcium phosphate cement apical barrier. J Endodon 1997; 23:174-7.

22. Dow, PR, Ingle, JI. Isostope determination of root canal failure. Oral Surg 1955; 8:1100-4.

23. Fuss, $Z$, et al. Comparative sealing quality of gutta-percha following the use of the McSpadden Compactor and the Engine Plugger. J Endodon 1985; 11:117-121.

24. Mattison, GD, von Fraunhofer, JA. Electrochemical microleakage study of endodontic sealer cements. Oral Surg 1983:55:402-7.

25. Torabinejad, $M$, et al. In vitro bacterial penetration of coronally unsealed endodontically treated teeth. J Endodon 1990;16:566-69.

26. Ainley, JE. Fluorometric assay of the apical seal of root canal fillings. Oral Surg Oral Med Oral Path 1970; 29:753-62.

27. Torabinejad, $M$, et al. Scanning electron microscopic study of root canal obturation using thermoplasticized gutta-percha. J Endodon 1978; 4:245-50. 
28. Matloff, IR, et al. A comparison of methods used in root canal sealability studies. Oral Surg 1982;53: 203-8.

29. Goldman, $M$, et al. The usefulness of dye-penetration studies reexamined. Oral Surg, Oral Med, Oral Path 1989; 67:327-32.

30. Spangberg, LSW, et al. Influence of entrapped air on the accuracy of leakage studies using dye penetration methods. J Endodon 1989; 15:548-51.

31. Kersten, HW, Moorer, WR. Particles and molecules in endodontic leakage. Int Endo Jrnl 1989:22:118-124.

32. Dumsha T, Hovland EJ. Evaluation of long-term calcium hydroxide treatment in avulsed teeth-an in vivo study. Int Endo Jrnl 1995:28:7-11.

33. Eldeeb, $M E$, et al. Apical leakage in relation to radiographic density of gutta-percha using different obturation techniques. J Endodon 1985; 11:25-9.

34. Hopkins, JH, et al. McSpadden versus lateral condensation: the extent of apical microleakage. J Endodon 1986; 12:198-201.

35. Robertson, DC,Leeb, IJ. The evaluation of a transparent tooth model system for the evaluation of endodontically filled teeth. J Endodon 1982; 8: 317-321

36. Roda, RS, Gutmann, JL. Reliability of reduced air pressure methods used to assess the apical seal. Int Endo Jrnl 1995;28:154-162. 
37. Wong, $M$, et al. Comparison of gutta-percha filling techniques, compaction (mechanical), vertical (warm), and lateral condensation techniques, part I. J Endodon 1981; 7:551-58.

38. Dalat, DM, Spangberg, LSW. Comparison of apical leakage in root canals obturated with various gutta-percha techniques using a dye vacuum tracing method. J Endodon 1994; 20:315.

39. Schilder, H. Filling root canals in three dimensions. Dental Clinics of North America 1967:723-744.

40. Reader, CM, et al. Effect of three obturation techniques on the filling of lateral canals and the main canal. J Endodon 1983; 19: 404-8.

41. Simlin, DR, et al. A comparison of stresses produced during lateral and vertical condensatiion using engineering models. J Endodon 1986; 12:235.

42. Narracott, P. An in vitro comparison of the single cone and lateral condensation technique using 'friction-fitted' and 'solvent dipfitted' primary gutta-percha cones. Aust Dent J 1989;34:49-51.

43. Zidan $O$, et al. Obturation of root canals using the single cone guttapercha technique and dentinal bonding agents. Int Endo Jrnl 1987:21:128-132.

44. Dalat, DM, Onal, B. Apical leakage of a new glass ionomer root canal sealer. J Endodon 1998:24:161-3.

45. Beatty, RG. The effect of standard or serial preparation on single cone obturations. Int Endo Jrnl 1987; 20: 276-281.

APPENDIX A 
DATA SPREADSHEET EXAMINER A 
Data Spreadsheet (Examiner A)

\begin{tabular}{|l|l|l|l|l|l|l|l|}
\hline $\begin{array}{l}\text { Tooth } \\
\text { ID \# }\end{array}$ & $\begin{array}{l}\text { Linear } \\
\text { Leak } \\
(\mathrm{mm})\end{array}$ & $\begin{array}{l}\text { Tooth } \\
\text { ID \# }\end{array}$ & $\begin{array}{l}\text { Linear } \\
\text { Leak } \\
(\mathrm{mm})\end{array}$ & $\begin{array}{l}\text { Tooth } \\
\text { ID \# }\end{array}$ & $\begin{array}{l}\text { Linear } \\
\text { Leak } \\
(\mathrm{mm})\end{array}$ & $\begin{array}{l}\text { Tooth } \\
\text { ID \# }\end{array}$ & $\begin{array}{l}\text { Linear } \\
\text { Leak } \\
(\mathrm{mm})\end{array}$ \\
\hline A1 & 0.0 & B1 & 0.0 & C1 & 0.0 & D1 & 0.0 \\
\hline A2 & 0.0 & B2 & 0.0 & C2 & 0.0 & D2 & 0.0 \\
\hline A3 & 0.0 & B3 & 0.0 & C3 & 0.0 & D3 & 0.2 \\
\hline A4 & 0.0 & B4 & 0.3 & C4 & 0.0 & D4 & 0.0 \\
\hline A5 & 0.8 & B5 & 0.0 & C5 & 0.0 & D5 & 0.0 \\
\hline A6 & 0.0 & B6 & 0.0 & C6 & 0.0 & D6 & 0.0 \\
\hline A7 & 0.9 & B7 & 0.0 & C7 & 0.0 & D7 & 0.0 \\
\hline A8 & 0.0 & B8 & elim & C8 & 0.6 & D8 & 0.0 \\
\hline A9 & 0.0 & B9 & 1.0 & C9 & 0.0 & D9 & 0.0 \\
\hline A10 & 0.0 & B10 & 0.0 & C10 & 0.0 & D10 & 0.0 \\
\hline A11 & 0.4 & B11 & 0.0 & C11 & 0.0 & D11 & elim \\
\hline A12 & 0.0 & B12 & 0.7 & C12 & 0.0 & D12 & 1.4 \\
\hline A13 & 0.0 & B13 & 0.0 & C13 & 0.0 & D13 & 0.0 \\
\hline A14 & 0.5 & B14 & 0.0 & C14 & 0.0 & D14 & 0.0 \\
\hline A15 & 0.0 & B15 & 0.0 & C15 & 0.5 & D15 & 3.1 \\
\hline A16 & 0.0 & B16 & 0.2 & & & D16 & 0.0 \\
\hline & & & & & D17 & 0.0 \\
\hline P0S1 & 8.5 & POS 2 & 7.8 & NEG 1 & 0.0 & NEG 2 & 0.0 \\
\hline
\end{tabular}


APPENDIX B

DATA SPREADSHEET

EXAMINER B 
Data Spreadsheet (Examiner B)

\begin{tabular}{|l|l|l|l|l|l|l|l|}
\hline $\begin{array}{l}\text { tooth } \\
\text { ID \# }\end{array}$ & $\begin{array}{l}\text { Linear } \\
\text { Leak } \\
(\mathrm{mm})\end{array}$ & $\begin{array}{l}\text { Tooth } \\
\text { ID \# }\end{array}$ & $\begin{array}{l}\text { Linear } \\
\text { Leak } \\
(\mathrm{mm})\end{array}$ & $\begin{array}{l}\text { Tooth } \\
\text { ID \# }\end{array}$ & $\begin{array}{l}\text { Linear } \\
\text { Leak } \\
(\mathrm{mm})\end{array}$ & $\begin{array}{l}\text { Tooth } \\
\text { ID \# }\end{array}$ & $\begin{array}{l}\text { Linear } \\
\text { Leak } \\
(\mathrm{mm})\end{array}$ \\
\hline A1 & 0.0 & B1 & 0.0 & C1 & 0.0 & D1 & 0.0 \\
\hline A2 & 0.0 & B2 & 0.0 & C2 & 0.0 & D2 & 0.0 \\
\hline A3 & 0.0 & B3 & 0.0 & C3 & 0.0 & D3 & 0.4 \\
\hline A4 & 0.0 & B4 & 0.5 & C4 & 0.0 & D4 & 0.0 \\
\hline A5 & 0.7 & B5 & 0.0 & C5 & 0.0 & D5 & 0.0 \\
\hline A6 & 0.0 & B6 & 0.0 & C6 & 0.0 & D6 & 0.0 \\
\hline A7 & 0.9 & B7 & 0.0 & C7 & 0.0 & D7 & 0.0 \\
\hline A8 & 0.0 & B8 & elim & C8 & 1.0 & D8 & 0.0 \\
\hline A9 & 0.0 & B9 & 1.1 & C9 & 0.0 & D9 & 0.0 \\
\hline A10 & 0.0 & B10 & 0.0 & C10 & 0.0 & D10 & 0.0 \\
\hline A11 & 0.4 & B11 & 0.0 & C11 & 0.0 & D11 & elim \\
\hline A12 & 0.0 & B12 & 0.5 & C12 & 0.0 & D12 & 1.4 \\
\hline A13 & 0.0 & B13 & 0.0 & C13 & 0.0 & D13 & 0.0 \\
\hline A14 & 0.7 & B14 & 0.0 & C14 & 0.0 & D14 & 0.0 \\
\hline A15 & 0.0 & B15 & 0.0 & C15 & 0.5 & D15 & 3.0 \\
\hline A16 & 0.0 & B16 & 0.3 & & & D16 & 0.0 \\
\hline POS1 & 8.0 & POS 2 & 7.8 & NEG 1 & 0.0 & NEG 2 & 0.0 \\
\hline
\end{tabular}


APPENDIX $C$

INSTRUMENTATION AND OBTURATION DATA COLLECTION SPREADSHEET 
Instrumentation and Obturation Data Collection Spreadsheet

\begin{tabular}{|c|c|c|c|c|c|c|c|c|c|}
\hline ID & Tooth \# & WL & MAF & sp & ID & Tooth \# & WL & MAF & Sprdrs \\
\hline $1 A$ & 9 & 14.0 & 0.600 & 3 & $2 A$ & $19 D$ & 10.0 & 0.600 & 4 \\
\hline $1 B$ & 20 & 14.0 & 0.600 & 2 & $2 B$ & $3 P$ & 15.0 & 0.465 & 2 \\
\hline $1 C$ & $3 P$ & 13.0 & 0.600 & 4 & $2 C$ & $18 D$ & 11.0 & 0.600 & 3 \\
\hline $1 D$ & $18 D$ & 12.0 & 0.600 & 3 & $2 D$ & 21 & 13.5 & 0.465 & 2 \\
\hline $1 \mathrm{E}$ & 7 & 11.5 & 0.600 & 4 & $2 E$ & $18 D$ & 13.0 & 0.360 & 2 \\
\hline $1 \mathrm{~F}$ & $19 D$ & 11.0 & 0.600 & 4 & $2 F$ & 24 & 13.0 & 0.360 & 2 \\
\hline $1 G$ & $14 P$ & 11.0 & 0.600 & 3 & $2 G$ & 11 & 13.0 & 0.465 & 4 \\
\hline $1 \mathrm{H}$ & $19 D$ & 14.0 & 0.350 & 2 & $2 \mathrm{H}$ & ELIMIN & ATED & - FRAC & TURED \\
\hline $1 \mathrm{I}$ & $19 D$ & 14.0 & 0.600 & 3 & $2 I$ & $30 D$ & 12.0 & 0.600 & 4 \\
\hline $1 \mathrm{~J}$ & 21 & 14.5 & 0.400 & 1 & $2 \mathrm{~J}$ & $18 D$ & 12.0 & 0.360 & 3 \\
\hline $1 \mathrm{~K}$ & $30 D$ & 13.0 & 0.400 & 2 & $2 K$ & 6 & 18.0 & 0.360 & 1 \\
\hline $1 L$ & $15 P$ & 12.5 & 0.450 & 2 & $2 L$ & 310 & 12.0 & 0.465 & 2 \\
\hline $1 M$ & 11 & 17.0 & 0.450 & 1 & $2 M$ & 310 & 12.0 & 0.360 & 2 \\
\hline $1 \mathrm{~N}$ & $14 P$ & 14.0 & 0.450 & 1 & $2 \mathrm{~N}$ & 8 & 12.0 & 0.600 & 2 \\
\hline 10 & 190 & 13.0 & 0.350 & 1 & 20 & $19 D$ & 13.0 & 0.600 & 3 \\
\hline $1 \mathrm{P}$ & $15 P$ & 13.0 & 0.450 & 2 & $2 P$ & 28 & 17.5 & 0.360 & 1 \\
\hline
\end{tabular}

\begin{tabular}{ccccc} 
ID & Tooth \# & WL & MAF & Sprdrs \\
\hline \hline $3 A$ & $18 D$ & 11.0 & 0.465 & 1 \\
$3 B$ & 8 & 13.0 & 0.465 & 1 \\
$3 C$ & 8 & 14.0 & 0.600 & 0 \\
$3 D$ & 10 & 13.0 & 0.360 & 0 \\
$3 E$ & 28 & 13.0 & 0.465 & 0 \\
$3 F$ & $15 P$ & 14.0 & 0.360 & 0 \\
$3 G$ & $3 P$ & 14.0 & 0.279 & 0 \\
$3 H$ & $2 P$ & 13.5 & 0.600 & 1 \\
$3 I$ & $15 P$ & 12.0 & 0.600 & 1 \\
$3 J$ & $2 P$ & 12.0 & 0.600 & 1 \\
$3 K$ & 21 & 11.0 & 0.360 & 0 \\
$3 L$ & 13 & 13.0 & 0.465 & 1 \\
$3 M$ & $3 P$ & 10.0 & 0.600 & 1 \\
$3 N$ & $30 D$ & 13.5 & 0.465 & 1 \\
30 & $2 P$ & 10.0 & 0.465 & 0
\end{tabular}

\begin{tabular}{ccccc} 
ID & Tooth \# & WL & MAF & Sprdrs \\
\hline \hline $4 A$ & 28 & 16.0 & 0.360 & NA \\
4B & 11 & 12.0 & 0.360 & NA \\
4C & $30 D$ & 12.0 & 0.360 & NA \\
4D & $19 D$ & 12.5 & 0.360 & NA \\
4E & $14 P$ & 12.0 & 0.465 & NA \\
4F & 10 & 14.0 & 0.465 & NA \\
$4 G$ & $18 D$ & 13.0 & 0.600 & NA \\
4H & $19 D$ & 14.0 & 0.465 & NA \\
$4 I$ & $19 D$ & 12.0 & 0.600 & NA \\
$4 J$ & 11 & 16.0 & 0.465 & NA \\
$4 K$ & $E L I M I N A T E D$ & $-F R A C T U R E D$ \\
$4 L$ & 26 & 13.5 & 0.279 & NA \\
$4 M$ & 23 & 14.0 & 0.279 & NA \\
$4 N$ & $19 D$ & 12.0 & 0.600 & NA \\
40 & $30 D$ & 12.0 & 0.600 & NA \\
$4 P$ & $30 D$ & 14.0 & 0.600 & NA \\
$4 Q$ & $30 D$ & 15.0 & 0.465 & NA
\end{tabular}




\section{ABSTRACT}

The purpose of this study was to evaluate the apical seal provided by a new gutta percha product (Diadent DiaPro .04 and .06 taper gutta percha points), using four different obturation techniques. Null hypotheses were 1) There is no difference in mean apical leakage among the four experimental groups, 2) There is no difference in the presence of apical leakage among the four groups.

Sixty eight canals of extracted human teeth were instrumented with ProFile Series 29, 0.06 taper rotary files (PRO-29). Experimental group 1 was instrumented with the PRO-29 files $2.0 \mathrm{~mm}$ short of working length and the apical $2.0 \mathrm{~mm}$ was instrumented with an ISO hand file. All other experimental groups were instrumented to working length with the PRO-29

files. Canals were obturated with Roth's 801 endodontic sealer and the following: Group 1) cold lateral condensation using an ISO size master gutta percha point which matched the size of an ISO master apical file used to prepare the apical $2.0 \mathrm{~mm}$; Group 2) cold lateral condensation using a DiaPro 
0.04 taper master gutta percha point: Group 3) warm vertical hybrid condensation using a DiaPro 0.06 taper master gutta percha point; Group 4) single cone obturation using a DiaPro 0.06 taper master gutta percha point. Roots were placed in India ink dye under vacuum and remained in dye for an additional 72 hours. They were rendered transparent and leakage was measured using an intraoral microscope.

The presence of leakage and the mean apical leakage for each experimental group was compared. The results of the study supported both of the null hypotheses. Leakage was observed in approximately $25 \%$ of the roots in each experimental group. There was no statistically significant difference among the groups for the presence of leakage (Chi Square, $p=0.94)$. There was no significant difference in mean linear apical leakage among the groups (Kruskall-Wallis, $\mathrm{p}=0.94$ ).

This in vitro study supports the use of the Diadent DiaPro 0.04 and 0.06 taper gutta percha points to obturate canals instrumented with the ProFile Series 29, 0.06 taper rotary files. 


\section{CURRICULUM VITAE}

Name: A. L. Christopher Kayafas

Date of Birth: March 9, 1967

Place of Birth: Ashtabula, Ohio

Spouse: Lisa Renee Kayafas

Children: Aristotle Lucas Kayafas, Noah Christopher Kayafas

Education:

$\begin{array}{lll}\text { Duquesne University } & \text { B.S. } & 1989\end{array}$

West Virginia University
School of Dentistry
D.D.S.
1997 